Check for updates

Cite this: RSC Adv., 2018, 8, 491

Received 10th September 2017 Accepted 14th December 2017

DOI: $10.1039 / c 7 r a 10075 b$

rsc.li/rsc-advances

\section{Transparent superhydrophobic hollow films (TSHFs) with superior thermal stability and moisture resistance $\uparrow$}

\begin{abstract}
Zhengwei Cai, ${ }^{a}$ Jinbin Lin ${ }^{* b}$ and Xinlin Hong (DD *a
Highly transparent superhydrophobic hollow films (contact angle, $165.7^{\circ}$ and sliding angle, $2.1^{\circ}$ ) have been prepared by using candle soot as a template, followed by methyltrimethoxysilane (MTMS) chemical vapor depostion (CVD) and calcination at $450{ }^{\circ} \mathrm{C}$, without the addition of dibutyl tin laurate (DBTL). The influence of deposition time on the superhydrophobicity and transparency of the as-prepared films was discussed herein to get the optimum performance film. The film shows high transparency (transmittance close to $90 \%$ ) when it was coated on a glass substrate. What is more, it shows good thermal stability and superior moisture resistance as well, retaining its superhydrophobicity after calcining up to $500{ }^{\circ} \mathrm{C}$ or even exposure to ambient conditions for 30 days. ${ }^{29} \mathrm{Si} \mathrm{NMR,} \mathrm{XPS} \mathrm{spectra} \mathrm{and} \mathrm{thermal} \mathrm{analysis} \mathrm{verify} \mathrm{the}$ existence of methyl groups linked with silicon matrix on film (low surface energy), while AFM and TEM analysis confirm the sub-100 nm roughness and hollow structure of the optimum film.
\end{abstract}

\section{Introduction}

Wettability is an important property for solid surfaces in many industrial processes as well as in our daily life. Superhydrophobic surfaces, with contact angle (CA) greater than $150^{\circ}$ and sliding angel (SA) lower than $5^{\circ}$, exhibit excellent water repellent properties and have attracted significant attention both in scientific research and industrial exploitation due to their potential applications in impermeable textiles, selfcleaning coatings, lab-on-chip devices, microfluidic devices and outdoor antennas or windows. ${ }^{1-7}$ Hierarchical micro/ nanosized roughness and low surface energy are the common causes of the observed superhydrophobicity of surfaces, which have been proved by some researchers during their studies in biological surfaces, such as the lotus leaf, the gecko, the namib desert beetle and water strider. ${ }^{8-13}$ The effect of hierarchical roughness and surface energy on the wettability of artificial and natural superhydrophobic surfaces has been demonstrated as well by Li et al. in thermodynamic approaches. ${ }^{\mathbf{1 4 - 1 6}}$

In the past few years, the fabrication of superhydrophobic surfaces has achieved a major progress. ${ }^{17-19}$ Superhydrophobic surfaces have been obtained from various routes, including etching and lithography, sol-gel processing, template-based method, physical/chemical vapor deposition (PVD/CVD), electrochemical deposition, self-assembly routes, electrospinning, phase

${ }^{a}$ College of Chemistry and Molecular Sciences, Wuhan University, Wuhan 430072, P. R. China.E-mail: hongxl@whu.edu.cn

${ }^{b}$ Skshu Paint Co., Ltd., Putian 351100, P. R. China

$\dagger$ Electronic supplementary information (ESI) available. See DOI: 10.1039/c7ra10075b separation means, and others. ${ }^{20-30}$ Yet, some problems still exist in the approaches described above, especially the optical transparency, which is crucially important for the application of superhydrophobic surfaces in solar cell panel and window treatment fields. However, few researchers paid their attention to improve the transparency of superhydrophobic surfaces.

It is a challenge for us to prepare superhydrophobic surfaces with good transparency. Superhydrophobic surfaces with high optical transparency have potential applications in the solar cell panel and the treatment of windows. To attain superhydrophobic surfaces, the surface roughness is necessary, but surface roughness also induces light scattering when the light falls on the surfaces. Light scattering is responsible for the blurring of superhydrophobic surfaces. Thus, to get transparency, light scattering should be lowered. In order to minimize the light scattering, surface roughness must be reduced below the wavelength of the incident light. Sub-100 nm roughness, which can lower the scattering intensity of incident light and give consideration to both superhydrophobicity and transparency, has been proved to be an effective route for producing superhydrophobic surfaces with high transparency in visible light. A few groups have made progress in designing sub-100 $\mathrm{nm}$ roughness and preparing transparent superhydrophobic surfaces in the recent past, such as the assembly and co-assembly of sub-100 nm nanoparticles by a simple dip-coating method, depositing fluorosilane on the sub$100 \mathrm{~nm}$ roughness to lower the surface energy, combining chemical vapor depostion (CVD) and template-based method. ${ }^{31-40}$ But most of above cases are limited by their strict preparation conditions, multi-step processing procedures, costly materials or poor ability to scale-up in practice. And the traditional silicon- 
containing film had to use dibutyl tin laurate (DBTL), which is very harmful.

Thermal stability is also an important property for the film, while most of the TSHFs change their properties when the treating temperature is too high. Zhang et al. reported multiwalled carbon nanotube@poly(dimethylsiloxane) (MWCNTs@PDMS) can only keep the superhydrophobic under $360{ }^{\circ} \mathrm{C} .{ }^{38}$ And Lin et al. reported CTMS can only keep the superhydrophobic under $400{ }^{\circ} \mathrm{C} .{ }^{41}$ The low thermal stability limits the application of TSHFs.

As mentioned above, there are few reports in literature focusing on the development of simple method for the preparation of highly transparent superhydrophobic hollow films by using easily obtained raw materials. Herein, we synthesized highly transparent superhydrophobic hollow films by using candle soot as template, followed by methyltrimethoxysilane (MTMS) CVD and calcination at $450{ }^{\circ} \mathrm{C}$. The influence of deposition time on the superhydrophobicity and transparency of as-prepared films was discussed hereafter to get the optimum performance film. The optimum performance film has high water contact angle $\left(165.7^{\circ}\right)$, low sliding angle $\left(2.1^{\circ}\right)$ and high transmittance (closes to $90 \%$ ) when it was coated on glass substrate without using harmful DBTL. The selected film possesses an excellent thermal stability and moisture resistance, which retains its superhydrophobicity after calcining up to $500{ }^{\circ} \mathrm{C}$ or even exposing to ambient condition for 30 days.

\section{Experimental}

A general schematic of the preparation of transparent superhydrophobic hollow films is given in Fig. 1. The route and experiments for synthesis are described in detail in $\mathrm{ESI}_{\dagger} \dagger$ (online). Various technologies including ${ }^{29} \mathrm{Si}$ CP MAS NMR, X-ray photoelectron spectroscopy (XPS), thermal analysis, atomic force microscopy (AFM) and transmission electron microscopy (TEM) were conducted to confirm and characterize the structure, composition and morphology of the optimum film. The detailed characterizations are described in detail in ESI $\dagger$ (online).

\section{Results and discussion}

\subsection{FT-IR spectra of TSHFs}

The transparent superhydrophobic hollow films were scratched from substrates for further FT-IR analysis. Herein, we only measured TSHF samples from CVD time higher than $6 \mathrm{~h}$. This is due to that the amount of sample is too small to get for analysis when the CVD time is lower than $6 \mathrm{~h}$. The FT-IR spectra of TSHF samples from different CVD time $(8,10,12,16,20$ and $24 \mathrm{~h})$ are displayed in Fig. S1 (ESI $\dagger$ ). All samples show strong absorption bands between $1047 \mathrm{~cm}^{-1}$ and $1137 \mathrm{~cm}^{-1}$ and a peak located at $439 \mathrm{~cm}^{-1}$, which are related to the stretching and bending modes of Si-O-Si groups, respectively. Besides, peaks at $1274 \mathrm{~cm}^{-1}$ and $773 \mathrm{~cm}^{-1}$ can be observed on the spectra of TSHFs as well, indicating the existence of $-\mathrm{Si}-\mathrm{CH}_{3}$ groups on samples. The peaks around $2978 \mathrm{~cm}^{-1}$ are due to stretching and bending vibrations of $-\mathrm{CH}_{3}$ groups, while the weak flat peak at $3475 \mathrm{~cm}^{-1}$ is related to the slight remaining -OH groups on TSHF samples. The FT-IR spectra verify the existence of $-\mathrm{Si}-\mathrm{CH}_{3}$ groups, which also indicate minute amount of hydroxyl groups on TSHFs sample.

\subsection{Water CA, SA and transparency measurement of TSHFs}

The transparent superhydrophobic hollow films (TSHFs) were prepared by using candle soot as template, followed by MTMS CVD and calcination at $450{ }^{\circ} \mathrm{C}$. The influence of different CVD time on the water CA, SA and transparency of the obtained films is displayed in Fig. 2, and the inset photographs are the water drop profiles of corresponding samples. As shown in Fig. 2(a), the water contact angle of films increases by adding the CVD time, reaching $165.2^{\circ}$ when the CVD time is $10 \mathrm{~h}$, after that, the water contact angle of films increases slightly by further raising the CVD time of MTMS. Meanwhile, the sliding angle of films also responds to the CVD time changes, which decreases from $5.6^{\circ}$ for TSHF-8 to the minimum value of $2.1^{\circ}$ for TSHF-24. Note that too low CVD time can not achieve superhydrophobic films, such as 2, 4 and $6 \mathrm{~h}$ samples. It might be due to unformed shell and insufficient methyl groups on the shell are obtained for low

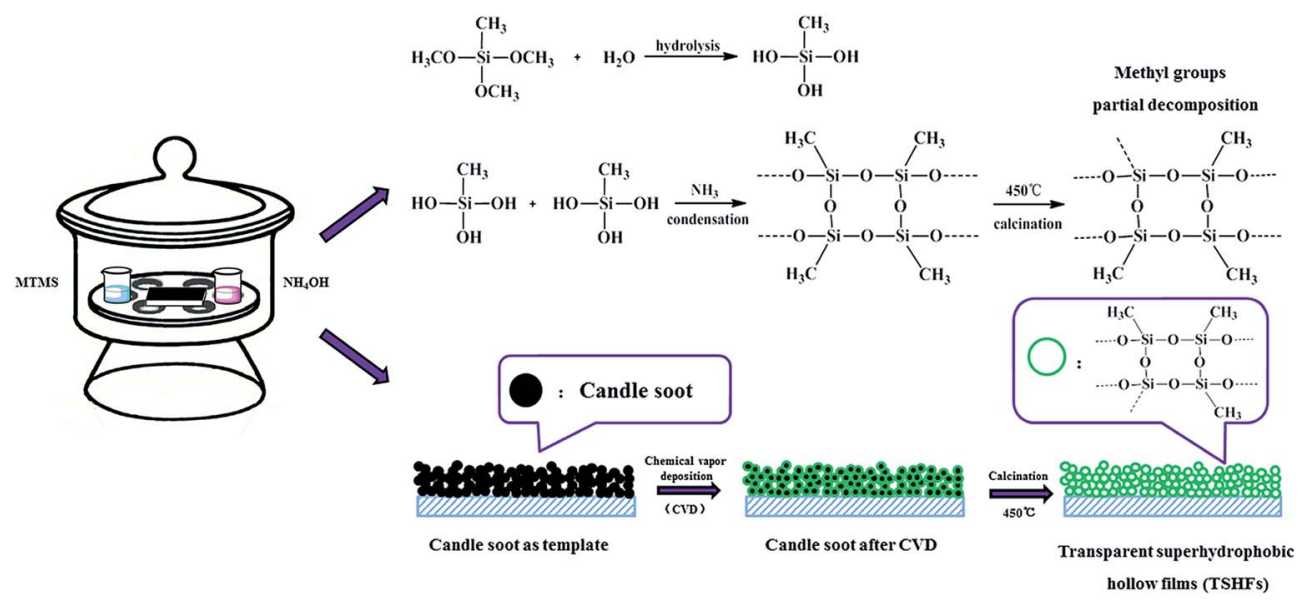

Fig. 1 A general schematic of the preparation of transparent superhydrophobic hollow films. 

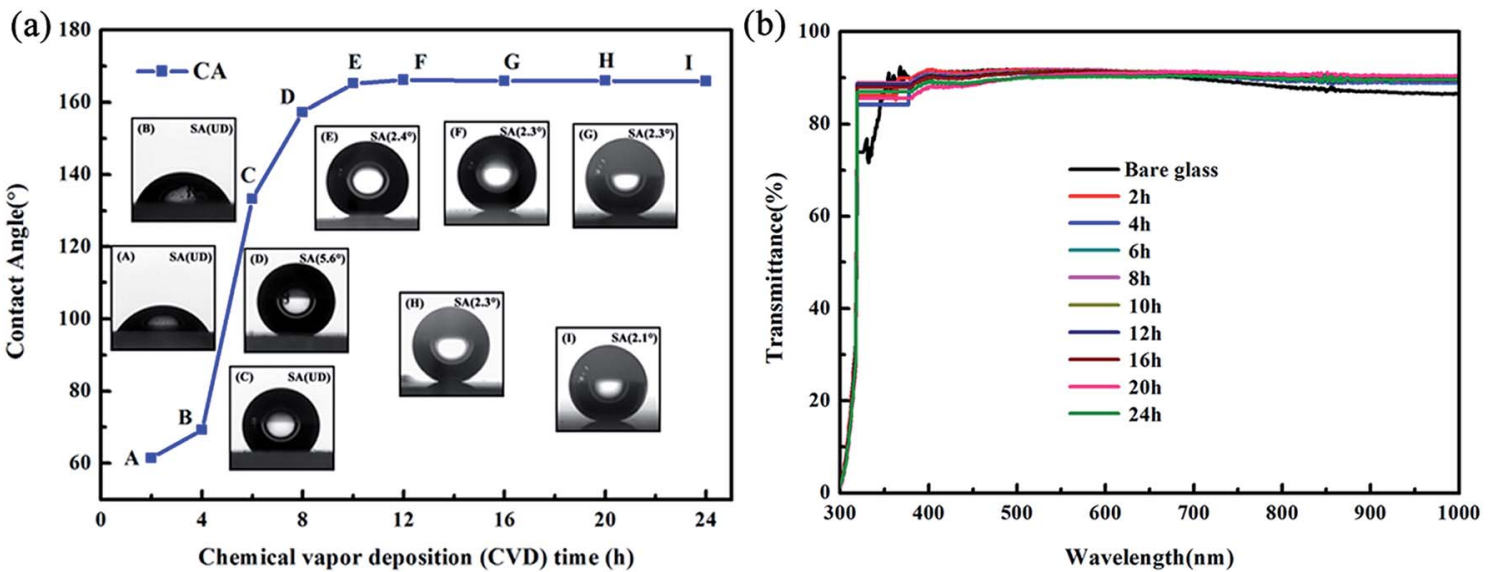

Fig. 2 The influence of different CVD time on the water contact angle (CA), sliding angel (SA) and transparency of films (a), note that the word "UD" in the images of the water drop profiles means undeterminable; the transmittance of bare glass and corresponding TSHFs coated glasses (b).

CVD time, which are not strong enough to render the films superhydrophobicity.

Fig. 2(b) presents the transmittance of bare glass and corresponding TSHFs coated glasses. It was found that the transmittance of TSHFs coated glasses is almost unchanged by adding the CVD time. All coated glasses maintain their optically transparency in the visible wavelength (transmittance closes to 90\%) when compared with bare glass. Even in high visible wavelength $(>750 \mathrm{~nm})$, the transmittance of coated glasses is somewhat higher than bare glass. It is ascribed to that sub$100 \mathrm{~nm}$ roughness from hollow films reduces the reflection of incident light and increases the transmittance. Similar observation has also been reported in the former publications. ${ }^{41,45}$

To aid the clearness, the transmittance of bare glass and TSHFs coated glasses in three visible wavelengths is summarized in Table S1 (ESI†). Clearly, TSHF-24 possesses the highest water contact angle $\left(165.7^{\circ}\right)$, lowest sliding angle $\left(2.1^{\circ}\right)$ and similar transparency with other film samples. Taking the water contact angle (CA), sliding angle (SA) and transparency of films into account together, TSHF-24 is chosen hereafter to investigate the structure, elemental composition, thermal stability, morphology and moisture resistance of as-prepared films.

\section{3. ${ }^{29} \mathrm{Si}$ CP MAS NMR, XPS spectra and thermal analysis of TSHF-24}

${ }^{29} \mathrm{Si} \mathrm{CP}$ (cross-polarization) MAS NMR is employed herein to get the detailed information of the binding structures among MTMS, as shown in Fig. S2 (ESI†). Strangely, two weak Q species' peaks can be detected on the ${ }^{29} \mathrm{Si}$ NMR spectrum of TSHF-24, indicating the presence of siloxane $\left(\mathrm{Q}^{4}, \mathrm{Si}(\mathrm{OSi})_{4}\right)$, free silanols $\left(\mathrm{Q}^{3}, \mathrm{Si}(\mathrm{OSi})_{3} \mathrm{OH}\right)$ groups on the sample, which is in conflict with the former publication. ${ }^{44}$ It is assigned to that the methyl groups partially decompose and form $\mathrm{Q}$ species when calcined at $450^{\circ} \mathrm{C}$ in air to remove the candle soot. Bidental $\left(\mathrm{T}^{2}\right)$ and tridental $\left(\mathrm{T}^{3}\right)$ anchoring structures, detected at $-56.7\left(\mathrm{~T}^{2}\right)$ and $-65.9\left(\mathrm{~T}^{3}\right) \mathrm{ppm}$, are adopted in the reaction among MTMS. Additionally, the peak strength of tridental $\left(\mathrm{T}^{3}\right)$ anchoring structure is higher than that of bidental $\left(\mathrm{T}^{2}\right)$ structure, indicating the high reactivity of MTMS. The ${ }^{29} \mathrm{Si}$ NMR spectrum of TSHF-24 also confirms the presences of methyl groups $\left(\mathrm{T}^{2}\right.$ and $\mathrm{T}^{3}$ ) on TSHF sample, which is in conformity with the FT-IR analysis above. The chemical shift $\delta_{\mathrm{Si}}$ and the anchoring structures among MTMS are summarized in Table S2 (ESI $\dagger$ ) to aid clearness.

XPS spectra are displayed as well in Fig. S3 $\uparrow$ to get the surface elemental composition of as-prepared film. The photoelectron peaks of O 1s, C 1s and Si 2p are located at $531.7 \mathrm{eV}, 283.7 \mathrm{eV}$ and $102.9 \mathrm{eV}$, on the spectrum of TSHF-24 sample. The spectra of $\mathrm{O} 1 \mathrm{~s}$ and $\mathrm{C} 1 \mathrm{~s}$ show only one peak at 531.7 and $283.7 \mathrm{eV}$, assigning to $-\mathrm{O}^{*}-\mathrm{Si}-$ and $-\mathrm{Si}-\mathrm{C}^{*} \mathrm{H}_{3}$ groups, respectively. ${ }^{42-46} \mathrm{The}$ spectrum of $\mathrm{Si} 2 \mathrm{p}$ can be divided into two peaks. A peak at $102.7 \mathrm{eV}$ is related to $-\mathrm{O}-\mathrm{Si}^{*}-\mathrm{CH}_{3}$, while the peak at $104.1 \mathrm{eV}$ is the corresponding peak of $\mathrm{Si}^{*} \mathrm{O}_{2} \cdot{ }^{42-46}$ The XPS spectra in Fig. 5 indicate the existence of methyl groups and silica matrix $\left(\mathrm{Si}^{*} \mathrm{O}_{2}\right)$ on TSHF-24 sample, which is in good accordance with the result of ${ }^{29} \mathrm{Si}$ NMR.

The thermal analysis of TSHF-24 is also shown in Fig. 3 to get the thermal stability and grafting density of methyl groups on

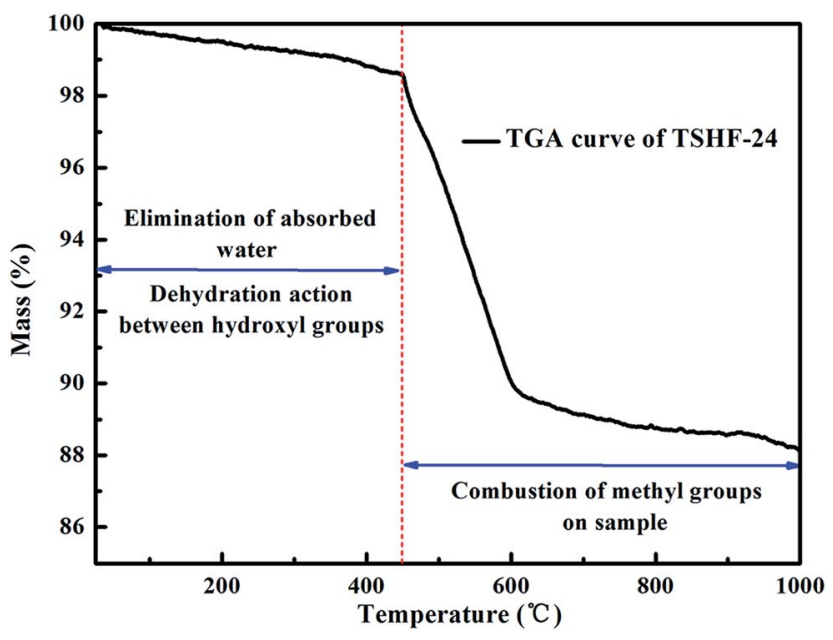

Fig. 3 The thermal analysis of TSHF-24 sample. 
(a)

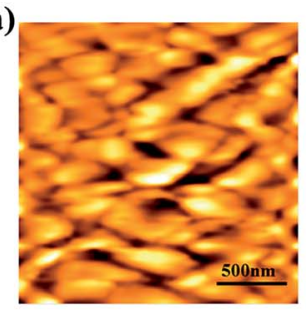

(b)

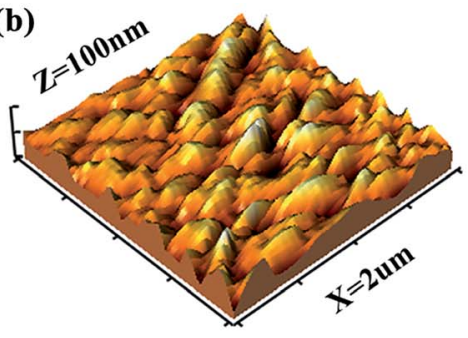

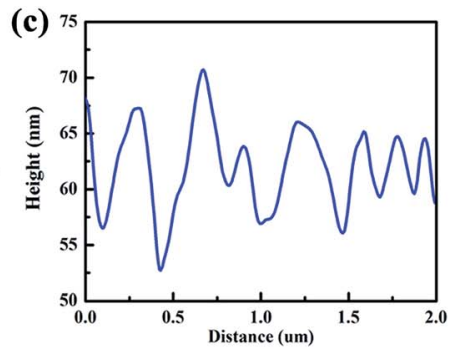

Fig. 4 2D AFM image (a), 3D AFM image (b) and height profile curve (c) of TSHF-24 sample.

sample. The slight weight loss up to $450{ }^{\circ} \mathrm{C}$ is due to the elimination of absorbed water and dehydration action between hydroxyl groups, the weight loss between 450 and $1000{ }^{\circ} \mathrm{C}$ is ascribed to the combustion of methyl groups on TSHF-24 sample. The whole weight loss of TSHF-24 is $11.61 \%$, and the weight loss assigning to methyl groups is $10.18 \%$. The grafting density of methyl groups on TSHF-24 can be calculated according to the following equation:

$$
\text { Methyl }\left(\mathrm{mol} \mathrm{g}^{-1}\right)=\frac{\mathrm{wt}_{\text {methyl }}}{\mathrm{MW}_{\text {methyl }}}
$$

$\mathrm{MW}_{\text {methyl }}$ stands for molecular weight of methyl groups, $15 \mathrm{~g}$ $\mathrm{mol}^{-1}$, while $\mathrm{wt}_{\text {methyl }}$ represents the weight loss related to methyl groups. Thus, the grafting density of methyl groups on film can be obtained, $6.79 \times 10^{-3} \mathrm{~mol} \mathrm{~g}^{-1}$.

\subsection{AFM analysis of TSHF-24}

A low surface energy and a sub-100 $\mathrm{nm}$ roughness have been considered to be account for the observed superhydrophobicity and transparency of TSHF-24, and the methyl groups linked with silica matrix (verified in Section 3.3) on the surface of film endow the TSHF-24 sample a low surface energy. AFM analysis of TSHF-24, as shown in Fig. 4, is conducted to verify the hierarchical structure and sub-100 nm roughness of film.

It can be observed from 2D AFM image that the surface of substrate has been coated homogeneously by TSHF-24 sample (Fig. 4(a)). In addition, a large quantity of sharp bumps stands on the surface of TSHF-24 sample (Fig. 4(b)), indicating hierarchical roughness of film. The height profile curve verifies the result of 3D AFM image, from which a frequently fluctuant height profile can be seen for TSHF-24 sample. The RMS roughness value of TSHF-24 can be calculated from the software, about $9.7 \mathrm{~nm}$, indicating the sub-100 $\mathrm{nm}$ roughness of film. So it could be deduced from the AFM images that the surface of TSHF-24 sample is hierarchical structure and sub$100 \mathrm{~nm}$ roughness.

\subsection{The TEM analysis and the optical photographs of water droplets experiment}

Fig. 5 presents the TEM images of TSHF-24 samples before and after calcination, the inset images are the closer look of corresponding samples. The optical photographs of water droplets on the treated glass are also displayed in Fig. 5. Clearly, candle soot exhibits a particle chain structure, which is made up of 42

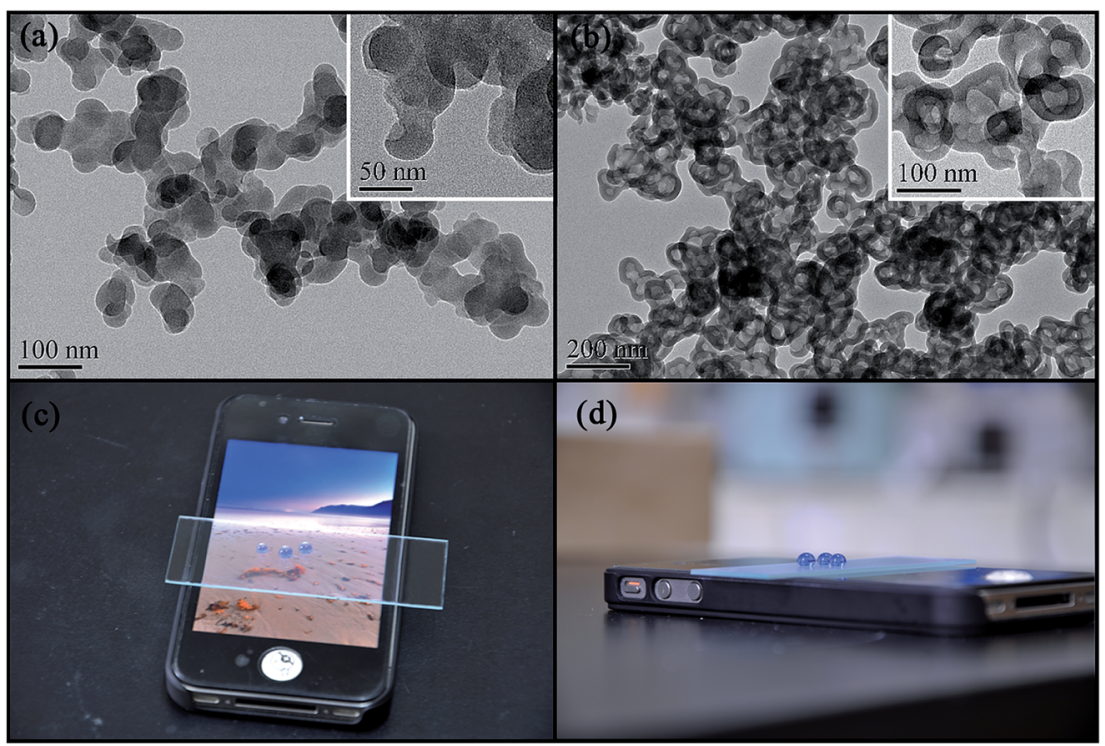

Fig. 5 TEM images of TSHF-24 samples before (a) and after (b) calcination (the inset images are the closer look of corresponding samples). The optical photographs of water droplets on the treated glass (c and d). 

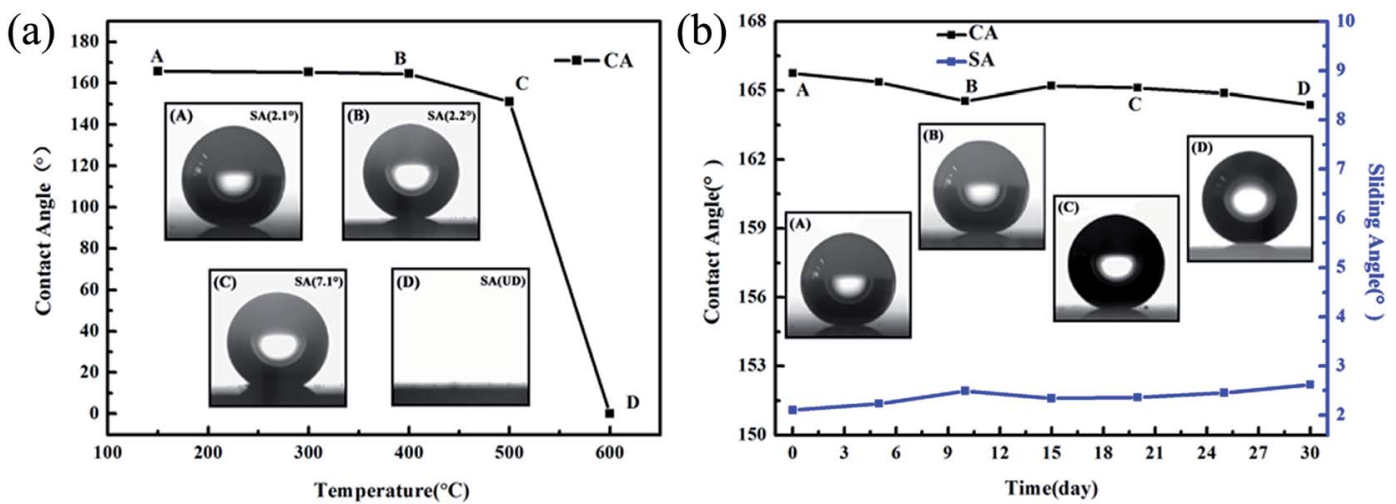

Fig. 6 The thermal stability (a) and moisture resistance (b) of TSHF-24 film.

Cassie-Baxter model

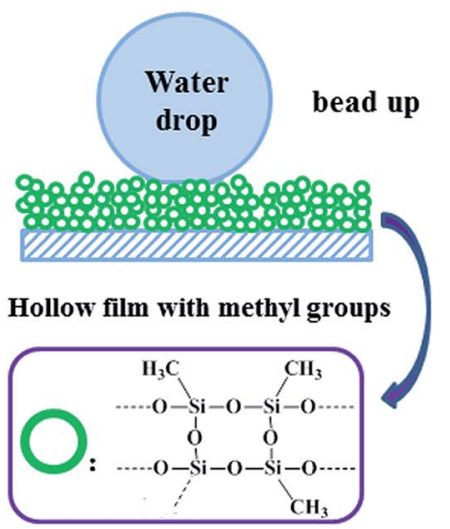

Wenzel model

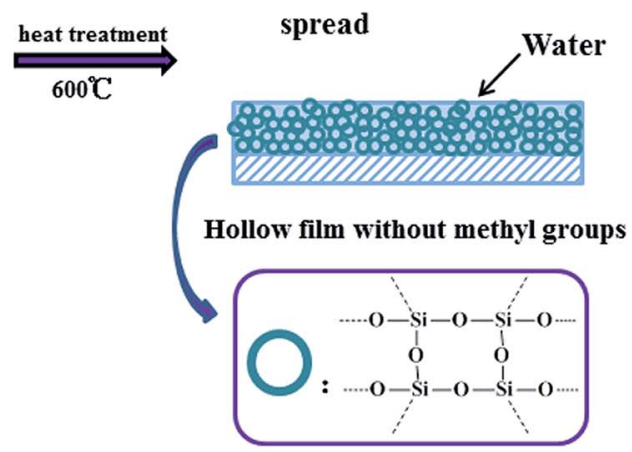

Fig. 7 The mechanism for the wettability change of TSHF-24 film after heat treatment at $600{ }^{\circ} \mathrm{C}$.

$\pm 5 \mathrm{~nm}$ spherical carbon balls. On these carbon balls, a distinct core-shell structure (Fig. 5(a)) can be observed on before treatment. After calcining in air at $450{ }^{\circ} \mathrm{C}$, the template is removed, and a hollow structure film (Fig. 5(b)) can be seen subsequently. The thickness of shell can be measured (about $20 \pm 5 \mathrm{~nm}$ ) as well from Fig. 5. Additionally, the dyed water droplets are rolling up on TSHF-24 coated glass (Fig. 5(c) and (d)) and the images underneath the coated glass are still visible (Fig. 5(c)), indicating the superhydrophobicity and transparency of obtained hollow film. Fig. 5 demonstrates the hollow structure, transparency and superhydrophobicity of TSHF-24 film.

\subsection{The thermal stability and moisture resistance of TSHF-}

24

The thermal stability of film, displayed in Fig. 6(a), was performed by calcining the coated glass at the temperature of 150 , 300, 400, 500 and $600{ }^{\circ} \mathrm{C}$ under air atmosphere for 1 hour, respectively. The water contact angle of film decreases slowly from $165.7^{\circ}$ to $164.5^{\circ}$, and the sliding angle of film declines slightly from $2.1^{\circ}$ to $2.2^{\circ}$ when raising the treating temperature of film up to $400{ }^{\circ} \mathrm{C}$, which might be due to the dehydration action between hydroxyl groups and elimination of the combined water in film. The superhydrophobicity of film shows apparent decrease at $500{ }^{\circ} \mathrm{C}$, when the treating temperature is up to $600{ }^{\circ} \mathrm{C}$, the wettability of film switches from superhydrophobic $\left(>160^{\circ}\right)$ to superhydrophilic $\left(0^{\circ}\right)$. The mechanism for the wettability change of film is proposed in Fig. 7. As known that Cassie-Baxter model and Wenzel model are common models for explaining the wettability of surfaces. In Wenzel's model, the rough surface could be wetted by driving off the trapped air by water, and the adhesion strength between water droplet and surface is large. However, in Cassie-Baxter model, the trapped air in rough surface could be hardly cleared by water, and the surface is difficult to be wetted. The adhesion strength between water droplet and surface is weak and even could be neglected in Cassie-Baxter model.

Cassie-Baxter model: ${ }^{47}$

$$
\cos \theta^{\mathrm{c}}=f\left(\cos \theta_{0}+1\right)^{-1}
$$

Wenzel model: ${ }^{48}$

$$
\cos \theta^{\mathrm{w}}=r \cos \theta_{0}
$$

where $\theta^{\mathrm{c}}$ is contact angle from Cassie-Baxter model, $\theta^{\mathrm{w}}$ is Wenzel contact angle and $\theta_{0}$ is the equilibrium contact angle on 
Table 1 Comparison with other superhydrophobic films in literatures

\begin{tabular}{|c|c|c|c|c|}
\hline & $\begin{array}{l}\text { Contact } \\
\text { angle }\left(^{\circ}\right)\end{array}$ & $\begin{array}{l}\text { Sliding } \\
\text { angel }\left({ }^{\circ}\right)\end{array}$ & $\begin{array}{l}\text { Transmittance } \\
(\%)\end{array}$ & Reference \\
\hline TSHFs & 165.7 & 2.1 & 90 & This work \\
\hline MWCNTs@PDMS & 165 & 3 & 83 & 38 \\
\hline APTEOS & 159.9 & 4.5 & 91 & 41 \\
\hline SPHSNs & 160 & 1 & 89 & 49 \\
\hline$(\mathrm{SSNs})_{1} /(\mathrm{SPHSNS})_{2}$ & 156 & 5.0 & 98.5 & 50 \\
\hline SCPs/DDS-SNPs & 153 & 5 & 92.67 & 51 \\
\hline POTS & 164 & 1 & 92.8 & 52 \\
\hline
\end{tabular}

flat surface. Herein, $r$ is the roughness factor, while $f$ is the fraction of liquid-solid contact. Note that $f$ decreases with the increase of the surface roughness. When $\theta_{0}>90^{\circ}, \theta^{\mathrm{w}}$ and $\theta^{\mathrm{c}}$ increase with the increase of surface roughness. When $\theta_{0}<90^{\circ}$, $\theta^{\mathrm{w}}$ and $\theta^{\mathrm{c}}$ decrease with the increase of surface roughness.

Clearly, the wettability of prepared film conforms to the model of Cassie-Baxter when the treating temperature is up to $500{ }^{\circ} \mathrm{C}$. The methyl groups from MTMS molecules lower the surface energy of film, while hierarchical sub-100 $\mathrm{nm}$ roughness of film increases the trapped air fraction and decreases fraction of liquidsolid contact. As a result, the film exhibits superhydrophobicity and the water droplets are rolling up on film. When the film experiences calcination at a temperature of $600{ }^{\circ} \mathrm{C}$, the methyl groups from MTMS are burned out, and the rough surface can be obtained. The film is in accord with Wenzel's model subsequently, on which the water could spread simply and shows superhydrophilicity. The results obtained from Fig. 6(a) are in good accordance with the thermal analysis above.

The moisture resistance of film, displayed in Fig. 6(b), is conducted by exposing the film to ambient condition for 30 days. Clearly, the prepared film possesses a good moisture resistance, which maintains its superhydrophobicity (higher than $165^{\circ}$ ) even after exposing to ambient condition for 30 days. What is more, it shows that the TSHFs film has very good performance after making comparison with other superhydrophobic films in literatures (Table 1). The TSHFs film has the biggest CA, and it also has very small SA and high transmittance at the same time.

\section{Conclusions}

In summary, the obtained optimum film exhibits superhydrophobicity (CA and SA, $165.7^{\circ}$ and $2.1^{\circ}$ ), high transparency (transmittance closes to $90 \%$ ), good thermal stability (up to 500 ${ }^{\circ} \mathrm{C}$ ) and superior moisture resistance, without the usage of DBTL. And it is interesting that the film switches from superhydrophobic $\left(>160^{\circ}\right)$ to superhydrophilic $\left(0^{\circ}\right)$ when it is calcined at $600{ }^{\circ} \mathrm{C}$. Further work will give insight into the relationship between experiment parameters (e.g. CVD time and candle soot thickness) and morphology (e.g. surface roughness and shell thickness) of as-prepared films.

\section{Conflicts of interest}

There are no conflicts to declare.

\section{References}

1 Q. Zhu, Q. Gao, Y. Guo, C. Q. Yang and L. Shen, Modified silica sol coatings for highly hydrophobic cotton and polyester fabrics using a one-step procedure, Ind. Eng. Chem. Res., 2011, 50, 5881-5888.

2 M. Manca, A. Cannavale, L. D. Marco, A. S. Aricò, R. Cingolani and G. Gigli, Durable superhydrophobic and antireflective surfaces by trimethylsilanized silica nanoparticles-based solgel processing, Langmuir, 2009, 25, 6357-6362.

3 Q. F. Xu, J. N. Wang and K. D. Sanderson, Organic-inorganic composite nanocoatings with superhydrophobicity, good transparency, and thermal stability, ACS Nano, 2010, 4, 2201-2209.

4 L. Sheng, W. Fajun, L. Wen and G. Qiao, Reversible wettability between superhydrophobicity and superhydrophilicity of $\mathrm{Ag}$ surface, Sci. China Mater., 2016, 59, 348-354.

5 M. S. Khalil-Abad and M. E. Yazdanshenas, Superhydrophobic antibacterial cotton textiles, J. Colloid Interface Sci., 2010, 351, 293-298.

6 X.-M. Li, D. Reinhoudt and M. Crego-Calama, What do we need for a superhydrophobic surface? A review on the recent progress in the preparation of superhydrophobic surfaces, Chem. Soc. Rev., 2007, 36, 1350-1368.

7 M. Ma and R. M. Hill, Superhydrophobic surfaces, Curr. Opin. Colloid Interface Sci., 2006, 11, 193-202.

8 L. Zhai, M. C. Berg, F. Ç. Cebeci, Y. Kim, J. M. Milwid, M. F. Rubner and R. E. Cohen, Patterned superhydrophobic surfaces: toward a synthetic mimic of the namib desert beetle, Nano Lett., 2006, 6, 1213-1217.

9 T. S. Kustandi, V. D. Samper, D. K. Yi, W. S. Ng, P. Neuzil and W. Sun, Self-assembled nanoparticles based fabrication of gecko foot-hair-inspired polymer nanofibers, Adv. Funct. Mater., 2007, 17, 2211-2218.

10 T. Pham, A.-P. Goldstein, J.-P. Lewicki, S.-O. Kucheyev, C. Wang, T.-P. Russell, et al., Nanoscale structure and superhydrophobicity of $\mathrm{sp} 2$-bonded boron nitride aerogels, Nanoscale, 2015, 7, 10449-10458.

11 L. Jiang, Y. Zhao and J. Zhai, A lotus-leaf-like superhydrophobic surface: a porous microsphere/nanofiber composite film prepared by electrohydrodynamics, Angew. Chem., 2004, 116, 4438-4441.

12 F. Shi, J. Niu, J. Liu, F. Liu, Z. Wang, X.-Q. Feng and X. Zhang, Towards understanding why a superhydrophobic coating is needed by water striders, Adv. Mater., 2007, 19, 2257-2261.

13 Y. Fang, G. Sun, Y. Bi and H. Zhi, Multiple-dimensional micro/nano structural models for hydrophobicity of butterfly wing surfaces and coupling mechanism, Science Bulletin, 2015, 60, 256-263.

$14 \mathrm{~W}$. Li and A. Amirfazli, Microtextured superhydrophobic surfaces: a thermodynamic analysis, Adv. Colloid Interface Sci., 2007, 132, 51-68.

$15 \mathrm{~W}$. Li and A. Amirfazli, Hierarchical structures for natural superhydrophobic surfaces, Soft Matter, 2007, 4, 462-466. 
16 W. Lee, W. Jung, S. Nagel and T. Odom, Stretchable Superhydrophobicity from Monolithic, Three-Dimensional Hierarchical Wrinkles, Nano Lett., 2016, 16, 3774-3779.

17 H. S. Lim, S. H. Park, S. H. Koo, Y.-J. Kwark, E. L. Thomas, Y. Jeong and J. H. Cho, Superamphiphilic janus fabric, Langmuir, 2010, 26, 19159-19162.

18 J. Zhang, G. Pu and S. J. Severtson, Fabrication of zinc oxide/ polydimethylsiloxane composite surfaces demonstrating oilfouling-resistant superhydrophobicity, ACS Appl. Mater. Interfaces, 2010, 2, 2880-2883.

19 T. Sun, G. Wang, L. Feng, B. Liu, Y. Ma, L. Jiang and D. Zhu, Reversible switching between superhydrophilicity and superhydrophobicity, Angew. Chem., Int. Ed., 2003, 43, 357360 .

20 X. Liu, Y. Xu, Z. Chen, K. Ben and Z. Guan, Robust and antireflective superhydrophobic surfaces prepared by CVD of cured polydimethylsiloxane with candle soot as a template, $R S C A d v$., 2015, 5, 1315-1318.

21 B. Qian and Z. Shen, Fabrication of superhydrophobic surfaces by dislocation-selective chemical etching on aluminum, copper, and zinc substrates, Langmuir, 2005, 21, 9007-9009.

22 H. Liu, L. Feng, J. Zhai, L. Jiang and D. Zhu, Reversible wettability of a chemical vapor deposition prepared $\mathrm{ZnO}$ film between superhydrophobicity and superhydrophilicity, Langmuir, 2004, 20, 5659-5661.

23 X. Liu, Y. Xu, K. Ben, Z. Chen, Y. Wang and Z. Guan, Transparent, durable and thermally stable PDMS-derived superhydrophobic surfaces, Appl. Surf. Sci., 2015, 339, 94101.

24 L. Feng, S. Li, H. Li, J. Zhai, Y. Song, L. Jiang and D. Zhu, Super-hydrophobic surface of aligned polyacrylonitrile nanofibers, Angew. Chem., 2002, 114, 1269-1271.

25 K. Acatay, E. Simsek, C. Ow-Yang and Y. Z. Menceloglu, Tunable, superhydrophobically stable polymeric surfaces by electrospinning, Angew. Chem., Int. Ed., 2004, 43, 52105213.

26 L. Xu and W. Li, A simple "two foil" approach to fabrication of hierarchical superhydrophobic surfaces, Colloids Surf., A, 2012, 404, 12-16.

27 Q. Xie, J. Xu, L. Feng, L. Jiang, W. Tang, X. Luo and C. C. Han, Facile creation of a super-amphiphobic coating surface with bionic microstructure, Adv. Mater., 2004, 16, 302-305.

28 J. T. Han, Y. Zheng, J. H. Cho, X. Xu and K. Cho, Stable superhydrophobic organic-inorganic hybrid films by electrostatic self-assembly, J. Phys. Chem. B, 2005, 109, 20773-20778.

29 X. Zhou, Z. Zhang, X. Xu, J. Yang, X. Men and X. Zhu, Facile fabrication of recoverable and stable superhydrophobic polyaniline films, Colloids Surf., A, 2012, 412, 129-134.

30 G. Yin, W. Xue, F. Chen and X. Fan, Self-repairing and superhydrophobic film of gold nanoparticles and fullerene pyridyl derivative based on the self-assembly approach, Colloids Surf., A, 2009, 340, 121-125.

31 X. Y. Ling, I. Y. Phang, G. J. Vancso, J. Huskens and D. N. Reinhoudt, Stable and transparent superhydrophobic nanoparticle films, Langmuir, 2009, 25, 3260-3263.
32 R. G. Karunakaran, C.-H. Lu, Z. Zhang and S. Yang, Highly transparent superhydrophobic surfaces from the coassembly of nanoparticles ( $\leq 100 \mathrm{~nm})$, Langmuir, 2011, 27, 4594-4602.

33 X. Deng, L. Mammen, H.-J. Butt and D. Vollmer, Candle soot as a template for a transparent robust superamphiphobic coating, Science, 2012, 335, 67-70.

34 Y. Xiu, F. Xiao, D. W. Hess and C. P. Wong, Superhydrophobic optically transparent silica films formed with a eutectic liquid, Thin Solid Films, 2009, 517, 1610-1615.

35 Y.-H. Lin, K.-L. Su, P.-S. Tsai, F.-L. Chuang and Y.-M. Yang, Fabrication and characterization of transparent superhydrophilic/superhydrophobic silica nanoparticulate thin films, Thin Solid Films, 2011, 519, 5450-5455.

36 J.-M. Wang, L.-D. Wang and L. Feng, One-step fabrication of fluoropolymer transparent films with superhydrophobicity by dry method, J. Appl. Polym. Sci., 2011, 120, 524-529.

37 A. Nakajima, K. Hashimoto, T. Watanabe, K. Takai, G. Yamauchi and A. Fujishima, Transparent superhydrophobic thin films with self-cleaning properties, Langmuir, 2000, 16, 7044-7047.

38 L. Zhang, C.-H. Xue, M. Cao, M.-M. Zhang, M. Li and J.-Z. Ma, Highly transparent fluorine-free superhydrophobic silica nanotube coatings, Chem. Eng. J., 2017, 320, 244-252.

39 A. Hooda, M.-S. Goyat, R. Gupta, M. Prateek, M. Agrawal and A. Biswas, Synthesis of nano-textured polystyrene/ZnO coatings with excellent transparency and superhydrophobicity, Mater. Chem. Phys., 2017, 193, 447-452.

$40 \mathrm{H}$. Budunoglu, A. Yildirim, M. O. Guler and M. Bayindir, Highly transparent, flexible, and thermally stable superhydrophobic ORMOSIL aerogel thin films, ACS Appl. Mater. Interfaces, 2011, 3, 539-545.

41 J. Lin, H. Chen, T. Fei and J. Zhang, Highly transparent superhydrophobic organic-inorganic nanocoating from the aggregation of silica nanoparticles, Colloids Surf., A, 2013, 421, 51-62.

42 H. M. Shang, Y. Wang, S. J. Limmer, T. P. Chou, K. Takahashi and G. Z. Cao, Optically transparent superhydrophobic silica-based films, Thin Solid Films, 2005, 472, 37-43.

43 J. Bravo, L. Zhai, Z. Wu, R. E. Cohen and M. F. Rubner, Transparent superhydrophobic films based on silica nanoparticles, Langmuir, 2007, 23, 7293-7298.

44 T. S. Deng, Q. F. Zhang, J. Y. Zhang, X. Shen, K. T. Zhu and J. L. Wu, One-step synthesis of highly monodisperse hybrid silica spheres in aqueous solution, J. Colloid Interface Sci., 2009, 329, 292-299.

45 S. Libertino, A. Scandurra, V. Aiello, F. Giannazzo, F. Sinatra, M. Renis and M. Fichera, Layer uniformity in glucose oxidase immobilization on $\mathrm{SiO}_{2}$ surfaces, Appl. Surf. Sci., 2007, 253, 9116-9123.

46 J. Lin, H. Chen, T. Fei, C. Liu and J. Zhang, Highly transparent and thermally stable superhydrophobic coatings from the deposition of silica aerogels, Appl. Surf. Sci., 2013, 273, 785-795.

47 A. B. D. Cassie and S. Baxter, Wettability of porous surfaces, Trans. Faraday Soc., 1944, 40, 546-551. 
48 R. N. Wenzel, Resistance of solid surfaces to wetting by water, Ind. Eng. Chem., 1936, 28, 988-994.

49 L. Gao and J. He, Surface hydrophobic co-modification of hollow silica nanoparticles toward large-area transparent superhydrophobic coatings, J. Colloid Interface Sci., 2013, 396, 152-159.

50 G. Zhou, J. He, L. Gao, T. Ren and T. Li, Superhydrophobic self-cleaning antireflective coatings on Fresnel lenses by integrating hydrophilic solid and hydrophobic hollow silica nanoparticles, RSC Adv., 2013, 3, 21789-21796.
51 Z. Chen, X. Liu, Y. Wang, J. Li and Z. Guagn, Highly transparent, stable, and superhydrophobic coatings based on gradient structure design and fast regeneration from physical damage, Appl. Surf. Sci., 2015, 359, 826-833.

52 T. Ren, Z. Geng, J. He, X. Zhang and J. He, A versatile route to polymer-reinforced, broadband antireflective and superhydrophobic thin films without high-temperature treatment, J. Colloid Interface Sci., 2017, 486, 1-7. 